\title{
Ethnic differences in the intention to use social media for health participation: a test of the social diversification hypothesis
}

\begin{abstract}
The goal of this study was to explain ethnic differences in the intention to use social media for health participation through the lens of the social diversification hypothesis. The data were collected from the sample of Israeli social media users $(\mathrm{N}=231)$. Ordinal regression was used for the multivariable analysis. It was found that Arab users were more likely than Israeli-born Jewish users to have an intention to engage in health participation on social media. The results imply that, in accordance with social diversification hypothesis, members of Arab minority population exhibit a greater intention than members of Jewish majority population to keep on benefitting from health participation on social media. Israeli public health officials should therefore encourage members of the Arab minority population to engage more in own healthcare and allocate more services to implement such healthcare.
\end{abstract}

Keywords: ethnic inequality, health, intention to use, social diversification, social media
Volume 9 Issue 5 - 2020

\author{
Dennis Rosenberg, ${ }^{1,2}$ Rita Mano, ${ }^{3}$ Gustavo S \\ Mesch ${ }^{4}$ \\ 'School of Public Health, University of Haifa, Israel \\ ${ }^{2}$ Department of Communication Studies, Ben-Gurion University \\ of the Negev, Israel \\ ${ }^{3}$ Department of Human Services, University of Haifa, Israel \\ ${ }^{4}$ Department of Sociology; Dean, University of Haifa, Israel
}

Correspondence: Dennis Rosenberg, PhD, School of Public Health, University of Haifa, Abba Hushi rd. 199, Haifa 3498838, Israel. Phone +972503327007. E-mail denrosen2@gmail.com

Received: September 07, 2020 | Published: September 30 , 2020

\section{Introduction}

Social media, including sites like YouTube, Facebook, and Twitter, has become a widely used platform for health-related activities others than health information seeking. ${ }^{1}$ For this study, we refer to these activities as health participation. ${ }^{2}$ For instance, it includes sharing of personal health experience, ${ }^{1}$ conducting discussions about the work of health professionals and institutions, or commenting on health-related content. $^{2}$

Health participation allows patients to develop autonomy in managing their health condition ultimately contributing to a greater satisfaction with the healthcare that they receive. ${ }^{3}$ However, the question remained is whether engagement in health participation on social media is stratified by ethnic background. This is especially important in multiethnic societies, given that in such societies health discrepancies exist along ethnic lines, ${ }^{4}$ leading to different extent of motivation to engage in health maintenance or improvement behaviors. ${ }^{5}$ Since sustained health participation may have ongoing benefits for personal health, ${ }^{6}$ it has a potential to offer even larger benefits for members of ethnic minorities, becoming a source of constantly provided health-related social support, advice, and knowledge.

In order to understand the studied phenomenon, we employ the well-established social diversification hypothesis. ${ }^{5}$ It suggests that members of ethnic minority groups, due to their poor health outcomes, are more motivated than members of the majority population (who typically have better health outcomes) to use the Internet for health purposes. ${ }^{5}$ Studies have generally supported this assumption, as Arab Internet users in Israel were found more likely than Jewish users to search for health information online. ${ }^{5,7}$ Thus, it is expected that Arab users will also intend to engage in health participation on social media in the future to a greater extent than the Jewish ones.
When examining the link between ethnic affiliation and the future intention to engage in health participation on social media, it is important to control for socio-demographic background. Gender: Women usually possess the role of health caregivers. ${ }^{5}$ Therefore, they are expected to engage in health participation on social media to a greater extent than men. ${ }^{8}$ Users of older age are typically less technology-savvy than younger users. ${ }^{5}$ Therefore, they are expected to intend to engage in health participation on social media to a lower extent than younger users. ${ }^{8,9}$ Higher levels of education reflect a greater likelihood of engagement in healthy behaviors. ${ }^{10}$ Therefore, individuals with academic education are expected to intend to engage in health participation on social media to a greater extent than those with lower levels of education. Family status: married individuals are expected to be less likely than the non-married ones to intend to engage in health participation on social media following the healthrelated social control that they both receive from their life partners and provide to them. ${ }^{11}$ The presence of chronic health condition typically motivates patients to go online to seek for health information and participate in online health-related discussions. ${ }^{5}$ Therefore, individuals with a chronic health condition are expected to intend to engage in health participation on social media to a greater extent than those without chronic condition.

\section{Israeli setting}

Israel is a multiethnic society, where about $75 \%$ of it is Jews, about $20 \%$ are Arabs, and the rest are members of other ethnic groups. Jews and Arabs reside mostly separately, whereas Arabs reside in peripheral regions distantly from the large urban localities. ${ }^{4}$ This poses a largescale obstacle for them in terms of health, since health specialist services are situated mostly in major urban localities. ${ }^{12}$ In addition, they have poorer health outcomes than the majority population. ${ }^{4}$ The Internet has been introduced as a venue for overcoming these health 
disparities. ${ }^{5}$ However, studies on health and Internet overlooked the intention to use social media for health participation. The present study will refer to ethnic differences in such intention.

\section{Methods}

\section{General description, data, and population}

This study was a part of a large-scale project addressing the association between health-related use of social media and changes in health behavior. The research in the project included two waves of the telephone survey. The data used in the current study were collected during the second wave of the survey that took place during April-June 2017. The sample included Israeli social media users, who participated in both waves of the survey $(\mathrm{N}=231)$. The informed consent was received from the participants before the start of each interview.

\section{Variables}

Dependent variable: Intention to use social media for health participation - measured by an item requiring to mention the extent of agreement (ranging from "1" (not at all) to "5" (to a very high extent)) with individuals' future intention to use social media for health participation. Following the ordinal nature of the outcome, ordinal logistic regression analysis has been performed. ${ }^{13}$

Independent variable: Ethnic origin - was categorized using series of dummy variables - Arabs, Former Soviet Union (FSU)born immigrants, and non-FSU-born immigrants. Israeli-born Jews represented an omitted category.

Control variables: Gender was a binary variable, with women as the reference category. Age was computed by subtracting the year of birth from the year of the survey. Level of education was a binary variable, with respondents having non-academic education as the reference category. Family status was a binary variable, with non-married or non-cohabiting respondents as the reference category. Chronic health condition - the original variable was recoded into a binary one, whereas respondents without chronic health disease (both in the past and in the present) represented the omitted category.

\section{Results}

The descriptive statistics of the sample are shown in Table 1. It can be seen that non-FSU-born immigrants are the oldest group, with a mean age of about 61 years. As to gender, only among Arabs from small localities, the percentage of men (about 58\%) exceeds that of women (about 42\%). As to education, FSU-born immigrants have the highest percentage of individuals with an academic education $(60 \%)$. As to family status, the highest percentage of married or cohabited individuals is in Israeli-born Jews group (about $80 \%$ ). A to the health status, non-FSU-born immigrants have the highest percentage of individuals with a chronic health condition (about 46\%).

Table 2 shows the results of the multivariable analysis predicting intention to use social media for health. The model demonstrated good fit to the data $\left(\right.$ Pearson $\left.\mathrm{Chi}^{2}(764)=796.35, \mathrm{p}>0.05\right)$.

It is seen that Arabs had a greater likelihood of intending to engage in health participation on social media than Jews $(b=0.89$, $\mathrm{p}<0.05$ ). Therefore, social diversification hypothesis was supported. The additional significant association was of education. Respondents with academic education intended to use social media for health participation to a lower extent than respondents with non-academic education $(b=-0.83, p<0.01)$.

Table I Sample statistics (in percentages) of the independent variables by ethnic origin (Arabs $n=28$; Israeli-born Jews $n=139$, FSU-born immigrants $n=25$, Non-FSU-born immigrants $n=39$, if not otherwise specified)

\begin{tabular}{lllll}
\hline & Israeli Jews & Arabs & FSU immigrants & Non-FSU immigrants \\
\hline $\begin{array}{llll}\text { Age, } \\
\text { mean }\end{array}$ & 48.3 & 36.6 & 51.1 & 61.1 \\
(SD) & $(I 2.7)$ & $(12.02)$ & $(18.6)$ & $(10.3)$ \\
Gender & & & & \\
Male & 49.6 & 57.1 & 40.0 & 41.0 \\
Female & 50.4 & 42.9 & 60.0 & 59.0 \\
Education & & & & \\
Academic & 57.6 & 39.3 & 60.0 & 43.6 \\
Non-academic & 42.4 & 60.7 & 40.0 & 56.4 \\
Family status & & $(\mathrm{n}=27)$ & & \\
Married & 79.9 & 51.9 & 72.0 & 76.9 \\
Non-married & 20.1 & 48.1 & 28.0 & 23.1 \\
Chronic health condition & & $(\mathrm{n}=27)$ & & \\
Yes & 29.0 & 7.4 & 36.0 & 46.2 \\
No & 71.0 & 92.6 & 64.0 & 53.8 \\
\hline
\end{tabular}

Table 2 Coefficients (standard errors) of the ordinal regression models predicting intention to use social media for health participation ( $\mathrm{n}=217)$

\begin{tabular}{ll}
\hline Not at all & -.78 \\
Low extent & .18 \\
Moderate extent & 1.04 \\
High extent & $1.63^{*}$ \\
Arab & $.89 *(.42)$ \\
FSU-born & $-.86(.47)$ \\
\hline
\end{tabular}


Table Continued...

\begin{tabular}{ll}
\hline Non-FSU-born & $-.04(.38)$ \\
Male & $-.25(.26)$ \\
Academic education & $-.83 * *(.27)$ \\
Age & $-.003(.01)$ \\
Married & $-.13(.31)$ \\
Chronic health condition & $.33(.30)$ \\
Model & $23.87 * *$ \\
-2 log likelihood & 546.79 \\
$\mathrm{R}$ & .111 \\
\hline
\end{tabular}

Note. $* \mathrm{p}<0.05 * * \mathrm{p}<0.01$

\section{Discussion}

The goal of this study was to understand ethnic differences in intention to use social media for health participation ${ }^{2}$ using social diversification hypothesis. ${ }^{5}$ The results of the study imply that members of the Arab minority population intend to use social media for health participation to a greater extent than members of the Jewish majority population, corresponding to similar findings in other studies on health and Internet. ${ }^{5,7}$ This may signal an insufficient amount of healthrelated social capital among the former ${ }^{5}$ or their greater perception of benefits the social media can provide for own health as compared to the latter. Therefore, public officials should provide greater resources to increase health-related social capital of the Arab population, and to encourage its members to use social media for health. In light of the findings, public healthcare officials and professionals could provide updated and relevant health information via social media, for example, by creating relevant pages (on Facebook) or channels (on YouTube).

Several limitations must be noted. First, the sample was relatively small. Second, the data is self-reported. Therefore, misclassifications in several variables are possible. ${ }^{14}$ Third, the scope of health participation may vary. Individuals may intend to actively participate in various types of health-related social media activities to a different extent. ${ }^{8}$ Future studies should explore this.

\section{Conclusion}

Overall, the findings of the study support social diversification hypothesis. The findings suggest that social media provides a good outlet for the members of the Arab minority group to improve their health outcomes. This may explain their greater desire to keep on using it for health participation compared to members of the Jewish majority group. Future studies should keep on investigating this issue while extending the understanding of specific benefits of health participation on social media as well as ways to enhance them for the minority population. This can be done by conducting qualitative research employing focus groups.

\section{Ethical approval}

The entire project was approved by the Ethics Committee of the University of Haifa (certificate \#246/17).

\section{Informed consent}

Informed consent was obtained from all individual participants included in the study.

\section{Funding}

This work was supported by the Israel Science Foundation under Grant \#376/14.

\section{Acknowledgments}

The authors would like to thank Mrs. Donna Bossin for a proofreading of the article.

\section{Conflicts of interest}

No potential competing interest was reported by the authors.

\section{References}

1. Zhao Y, Zhang J. Consumer health information seeking in social media: a literature review. Health Info Libr J. 2017;34:268-283.

2. Rosenberg D, Mano R, Mesch GS. Absolute monopoly, areas of control or democracy? Examining gender differences in health participation on social media. Comput Hum Behav. 2020;102:166-171.

3. Smailhodzic E, Attema S. Self-determination theory as an explaining mechanism for the effects of patient's social media use. In Proceedings of the international conference on information systems. 2016.

4. Saabneh AM. Ethnic health inequalities in unequal societies: morbidity gaps between Palestinians and Jews in Israel. Eur J Popul. 2015;31:445466.

5. Mesch GS. Ethnic origin and access to electronic health services. Health Inform J. 2016;22:791-803.

6. Zhang Y. Understanding the sustained use of online health communities from a self-determination perspective. J Assoc Inform Sci Technol. 2016;67:2842-2857.

7. Neumark Y, Lopez-Quintero C, Feldman BS, et al. Online health information seeking among Jewish and Arab adolescents in Israel: results from a national school survey. J Health Commun. 2013;18:1097-1115.

8. Pálsdóttir Á. Preferences in the use of social media for seeking and communicating health and lifestyle information. Inform Res: Int Electron J. 2014;19(4)

9. Jackson DN, Chou WYS, Coa KI, et al. Implications of social media use on health information technology engagement: data from HINTS 4 cycle 3. Transl Behav Med. 2016;6:566-576.

10. Cutler DM, Lleras-Muney A. Understanding differences in health behaviors by education. $J$ Health Econ. 2010;29:1-28.

11. August KJ, Sorkin DH. Marital status and gender differences in managing a chronic illness: the function of health-related social control. Soc Sci Med. 2010;71:1831-1838.

12. Popper-Giveon A, Keshet Y. It's every family's dream: choice of a medical career among the Arab minority in Israel. J Immigr Minor Health. 2016;18:1148-1158.

13. Raijman R, Semyonov M, Geffen R. Language proficiency among post1990 immigrants in Israel. J Ethn Migr Stud. 2015;41:1347-1371.

14. Koo M, Lu MC, Lin SC. Predictors of Internet use for health information among male and female Internet users: findings from the 2009 Taiwan National Health Interview Survey. Int J Med Inform. 2016;94:155-163. 